\title{
Lidil
}

Revue de linguistique et de didactique des langues

$58 \mid 2018$

L'enseignement et l'apprentissage de l'écrit académique à l'aide de corpus numériques

\section{Nicolas Laurent et Christelle Reggiani (dir.), Seuils du nom propre}

coll. « Études linguistiques et textuelles » (CREM, Université de Lorraine), Limoges, Lambert-Lucas, 2017, 194 p.

\section{Samia Ounoughi}

\section{CpenEdition}

\section{Journals}

Édition électronique

URL : http://journals.openedition.org/lidil/5195

DOI : 10.4000/lidil.5195

ISSN : $1960-6052$

Éditeur

UGA Éditions/Université Grenoble Alpes

Édition imprimée

ISBN : 978-2-37747-064-8

ISSN : $1146-6480$

\section{Référence électronique}

Samia Ounoughi, « Nicolas Laurent et Christelle Reggiani (dir.), Seuils du nom propre », Lidil [En ligne],

58 | 2018, mis en ligne le 02 novembre 2018, consulté le 24 septembre 2020. URL : http://

journals.openedition.org/lidil/5195; DOI : https://doi.org/10.4000/lidil.5195

Ce document a été généré automatiquement le 24 septembre 2020.

(c) Lidil 


\section{Nicolas Laurent et Christelle Reggiani (dir.), Seuils du nom propre}

coll. « Études linguistiques et textuelles » (CREM, Université de Lorraine), Limoges, Lambert-Lucas, 2017, 194 p.

\section{Samia Ounoughi}

\section{RÉFÉRENCE}

Nicolas Laurent et Christelle Reggiani (dir.), Seuils du nom propre, coll. « Études linguistiques et textuelles » (CREM, Université de Lorraine), Limoges, Lambert-Lucas, 2017,194 p.

1 Cet ouvrage collectif est issu du colloque international de linguistique et de stylistique «Seuils du nom propre » qui s'est tenu en mars 2015 à l'École normale supérieure de Lyon. Les 13 contributions en langue française visent toutes à explorer la nomination de personnes ou de personnages, une nomination aux seuils du nom propre (NP). Ainsi, l'ouvrage va au-delà de la description linguistique du NP et des syntagmes dans lesquels il intervient en investissant le champ de la stylistique. Les auteur(e)s y explorent les formes périphériques ou hybrides de dénominations individuelles en plus du NP et de ses modifications telles que les sobriquets, les surnoms ou les syntagmes nominaux phonétiques. Ils révèlent l'immense variété des créations auctoriales pour dénommer la personne ainsi que leurs enjeux sur le genre, l'évolution diachronique du patronyme, etc.

Les corpus sous étude dans ces contributions sont d'une grande variété. Ils couvrent des périodes de l'Histoire allant de l'Antiquité à nos jours en passant par le Moyen Âge et l'époque moderne (Anna Jaubert). Ils explorent également des genres aussi variés que le roman (Vanessa Obry), le conte (Emily Lombardo), l'autobiographie (Véronique Montémont) ou la bande dessinée (Agathe Cormier). Même la poésie est étudiée alors que les NP de personnes y figurent rarement (Federica Locatelli, Sylvain Dournel). Les derniers articles sont consacrés à l'analyse de sources non fictionnelles et 
multimodales, à l'oral et à l'écrit, notamment la presse et les autres organes médiatiques (Anna Arzoumanov, Paola Paissa, Dorgelès Houessou).

3 Tenant toujours compte à la fois des contextes historique et discursif de ces occurrences, ces articles questionnent la dénomination de l'individu réel ou du personnage de fiction à l'appui de l'analyse des particularités linguistiques et des processus discursifs qui construisent le lien entre le référent et le NP ou assimilé (antonomase inversée, exophore mémorielle, etc.) Les auteur(e)s montrent le parcours qui conduit au choix d'un élément ou d'éléments de catégories grammaticales diverses pour dénommer un individu ou un personnage de fiction (noms communs, onomatopées, schémas phonétiques de syntagmes ou autres). Ils distinguent des étapes de nomination qui vont de pair avec une évolution du sujet et/ou de l'économie du discours dans son ensemble, voire, l'évolution d'un genre (le roman médiéval chez Vanessa Obry). Aussi, la complexité de ces occurrences dénominatives aux seuils du NP est-elle également explorée dans sa nature variable, voire instable. Nicolas Laurent et Christelle Reggiani sondent aussi le rôle majeur de l'éditeur dans ses choix typographiques, notamment l'enjeu de la majuscule sur un même nom et les multiples possibilités d'interprétations qu'offrent ou imposent ces variations.

Les analyses sont menées à l'appui d'outils complémentaires comme la stylistique, la pragmatique ou l'analyse du discours par les corpus numérisés. Elles nous permettent d'envisager à quel point le champ du NP est vaste tant ses frontières s'étendent, nous invitant à parcourir des registres d'occurrences relevant aussi bien de la vie quotidienne (politique, justice, presse...) que de la fiction sous toutes ses formes. Donnons pour exemple l'article passionnant d'Agathe Cormier qui explore la motivation du NP dans une BD hilarante où les NP correspondent aux tics de langage des personnages. Elle fait également résonner/raisonner le silence, car elle étudie le cas du personnage-clé, celui qui n'a pas de nom. L'autobiographie est relue à l'aune des options multiples qui s'offrent à l'auteur de garder son nom dans le texte, de le modifier ou de le taire. Ici, Véronique Montémont engage toute une réflexion sur le rapport du NP à son référent. Dans un autre article, Emily Lombardo montre comment un auteur peut user des références communes avec son lectorat pour se les réapproprier et tisser une complicité toute particulière avec lui à travers les contes de La Fontaine.

$5 \quad$ L'ouvrage est loin d'avoir sondé la totalité des seuils du NP; il nous permet en revanche de saisir l'ampleur et la richesse de ce champ liminal et promet des recherches passionnantes à venir.

\section{AUTEURS}

\section{SAMIA OUNOUGHI}

LIDILEM, Université Grenoble Alpes 